\title{
Knowledge, Attitude and Practices Regarding Infant Feeding Practices Among Mothers
}

\author{
Dr. Maitry Shah ${ }^{1}$, Dr. Purvi Patel ${ }^{2}$, Dr. K. M. Mehariya ${ }^{3}$ \\ ${ }^{1}$ Resident Doctor, Department of Pediatrics, B. J. Medical College, Civil Hospital, Ahmedabad, India \\ ${ }^{2}$ Assistant Professor, Department of Pediatrics, B. J. Medical College, Civil Hospital, Ahmedabad, India \\ ${ }^{3}$ Professor, Department of Pediatrics, B. J. Medical College, Civil Hospital, Ahmedabad, India
}

\begin{abstract}
Aims \& Objectives: To study the knowledge and awareness of mothers towards infant feeding practices. Materials and Methods: Total 200 mothers of infants, coming to a tertiary care centre, Ahmedabad, on outpatient basis were interviewed using a predesigned questionnaire. Results: Out of the total, $24 \%$ mothers were illiterate. $89 \%$ knew about exclusive breast feeding up to 6 months. 82.67\% think that colostrum is good for baby.44.67\% mothers have given pre-lacteal feeds, tea and jaggery was most common.89\% mothers knew that they should take extra food during lactation. Father(42\%) most commonly help in feeding while $31.33 \%$ don't get any domestic help. $65.67 \%$ mothers have been counselled by doctor.71.06\% women consulted doctor for feeding problems. Most common reason of stopping breast feeding was inadequate milk secretion(46.67\%).11\% think that feeding should be stopped during illness. $75.33 \%$ women were completely satisfied with their feeding practices. Conclusion: The study highlights that there is vital need to improve the knowledge \& awareness in the society regarding community based care. We should also strive towards helping removing myths and wrong practices which are rampant in the community. Level of education has positive impact on infant feeding practices.
\end{abstract}

Keywords: Infant feeding, breastfeeding, attitude and practice

\section{Introduction}

Adequate nutrition during infancy and early childhood is essential to ensure the growth, health, and development of children to their full potential. Early nutritional deficits are also linked to long-term impairment in growth and health. There is evidence that adults who were malnourished in early childhood have impaired intellectual performance (1). They may also have reduced capacity for physical work $(2,3)$. The first two years of life provide a critical window of opportunity for ensuring children's appropriate growth and development through optimal feeding (4). Based on evidence of the effectiveness of interventions, achievement of universal coverage of optimal breastfeeding could prevent deaths occurring in children less than 2 years of age globally, while appropriate complementary feeding practices would result in an additional reduction in underfive mortality(5).

Breast milk provides immunologic protection against death from infectious diseases, such as diarrhoea, respiratory infections, otitis media, pneumonia and meningitis. Poor feeding practices are a major threat to social and economic development. Nutritional counselling is required to improve the infant feeding practices. This study was conducted to assess mother's knowledge regarding infant feeding and to assess the attitude and practices towards the recommended feeding practices.

India is a kaleidoscope of various cultures and traditions. A lot of the customs and practices have their effect over health including infant feeding practices. By assessing the knowledge, attitude and practices of mothers regarding their child's feeding, an overview can be obtained about the areas which need modifications and hence specific intervention strategies can be made to correct the same.

\section{Materials and Methods}

This cross-sectional study was conducted on mothers of children less than one year of age attending the outpatient department of a tertiary care centre at Ahmedabad city. An orally expressed consent was taken by the participating mothers. A total of 200 mothers were interviewed who were randomly selected from the outpatient department over a period of 3 months. A structured questionnaire was prepared for the study based on the national guidelines for infant and young child feeding issued by the government of India (6). These questionnaires were sent out, which were to be filled and returned. Illiterate mothers were asked to answer the questions orally and were filled in by volunteers. Attitude and practices of participants were included in the study.

\section{Results and Discussion}

Table 1 shows that the number of interviewed mothers of children aged less than 6 months and more than 6months attending the outpatient department were equal. Mothers of male children were more with $34 \%$ among infants less than 6 months and 32\% among infants more than 6 months.

Table 1: Age and sex of infants whose mothers were interviewed

\begin{tabular}{|l|l|l|}
\hline \multicolumn{1}{|c|}{ Age } & $<6$ months (\%) & $>6$ months (\%) \\
\hline Males & $66(33.0 \%)$ & $63(31.5 \%)$ \\
\hline Females & $39(19.5 \%)$ & $32(16.0 \%)$ \\
\hline Total & 105 & 95 \\
\hline
\end{tabular}




\section{International Journal of Science and Research (IJSR) \\ ISSN (Online): 2319-7064}

Index Copernicus Value (2013): 6.14 | Impact Factor (2014): 5.611

Table 2: Educational status of mother Education Number (\%) Knowledge (\%)

\begin{tabular}{|l|l|l|}
\hline \multicolumn{1}{|c|}{ Education } & Number (\%) & Knowledge (\%) \\
\hline Illiterate & $48(24.00 \%)$ & $32(66.67 \%)$ \\
\hline Literate/Primary school & $42(21.00 \%)$ & $27(64.28 \%)$ \\
\hline Middle school & $39(19.50 \%)$ & $27(69.23 \%)$ \\
\hline High school & $34(17.00 \%)$ & $25(73.52 \%)$ \\
\hline Intermediate & $11(5.50 \%)$ & $9(81.81 \%)$ \\
\hline Graduate or Postgraduate & $12(6.00 \%)$ & $11(91.67 \%)$ \\
\hline Professional or honours & - & - \\
\hline
\end{tabular}

Table 2 shows that highest percentages of mothers, $21 \%$ were literate with primary education followed by $19.5 \%$ of mothers who were educated upto middle school.24\% mothers were illiterate. $91.67 \%$ graduate mothers had good knowledge.

Table 3: Infant feeding attributes Attribute Number (\%)

\author{
Time of initiating breast feeding \\ Knowledge \\ Within $1 \mathrm{hr}$ of birth $-108(54.00 \%)$ \\ Between 1-4 hrs of birth $-35(17.5 \%)$ \\ Between 1-3 days of birth- 5(2.50\%) \\ Within 1st week of birth- $10(5.00 \%)$ \\ Practice \\ Within 1 hr of birth- 82(41.0\%) \\ Between 1-4 hrs of birth $-35(17.5 \%)$ \\ Between 1-3 days of birth- 21(10.5\%) \\ Within 1st week of birth- $12(6.00 \%)$ \\ Opinion about colostrums \\ Good 164(82.67\%) \\ Bad 36(18.33\%)
}

Exclusive breast feeding for 6 months

Knowledge

Exclusive breast feeding- 178(89.00\%)

Mixed feeding- $12(6.00 \%)$

Practice

Exclusive breast feeding- 112(56.00\%)

Mixed feeding- 57(28.5\%)

Prelacteal feeds

Given- 88(44.67\%)

Not given- 98(55.33\%)

Top milk used during mixed feeding $(n=47)$

Packaged milk- 24(51.06\%)

Goat's milk- 12(25.53\%)

Cow's milk- 11(23.4\%)

Formula milk- 3(6.38\%)

Buffalo's milk- 7(14.89\%)

Duration of breast feeding

6 months- $43(21.5 \%)$

12 months- $88(44.0 \%)$

18 months- $13(6.50 \%)$

24 months- 6(3.00\%)

Initiation of complementary feeding

6 months $136(68.0 \%)$

1 year $45(22.5 \%)$

2 year $5(2.50 \%)$

Others $14(7.00 \%)$

Attributes of complementary foods score

$<60 \%-75(37.5 \%)$

$60-80 \%-61(30.5 \%)$

$>80 \%-64(32.0 \%)$

\section{Counseller}

Doctor 130(65.67\%)

Relatives 28(14.67\%)

Local health worker $20(10.00 \%)$

Not counselled 33(16.67\%)

Aid/Support in feeding

Father $82(41.00 \%)$

Grandmother 56(28.00\%)

No help 62(31.33\%)

Continuation of breast feeding beyond 6 months

Continued 91(60.67)

Discontinued 59(39.33)

Reasons for discontinuing breast feeding

Inadequate milk secretion 92(46.67\%)

Not sucking well on breast $24(16.00 \%)$

Baby not gaining weight $13(8.67 \%)$

Mother got pregnant $12(8.00 \%)$

Breast abscess/sore nipples 9(6.00\%)

Baby became sick $8(5.33 \%)$

Mother became sick 2(1.33\%)

Feeding during illness

Continued $178(89.00 \%)$

Discontinued 22(11.00\%)

Consultation during illness

Doctor 142(71.06\%)

Relatives 38(19.33\%)

Friends $15(7.50 \%)$

None 5(2.50\%)

Table 3 shows that $54.00 \%$ of mothers had the knowledge about initiation of breast feeding within 1 hour of birth whereas $41.00 \%$ practiced it. $82.67 \%$ of mothers had a good opinion about colostrum. $89 \%$ mothers had the knowledge of exclusive breast feeding but only $56 \%$ practiced it. $44.67 \%$ of infants had received prelacteal feeds. The most common substance given was tea and jaggery. The most common top milk practiced was packaged milk (29.79\%) followed by goat's milk and cow's milk (25.53\%). majority of mothers $(44.00 \%)$ practiced breast feeding upto 12 months of age while only $3 \%$ breast fed upto 24 months. $68.00 \%$ of mothers initiated complementary feeding by 6 months of age. Doctor $(71.08 \%)$ was the most frequent counsellor regarding feeding followed by relatives(19.33\%).Fathers (41\%) most commonly support the mother in feeding. $60.67 \%$ mothers continued breast feeding beyond 6 months. Of the 39.33\% mothers who discontinued breast feeding the most common cause was inadequate milk secretion $(46.67 \%)$ followed by sucking difficulties by the baby(16\%).89\% continued feeding during illness.

Table 4: Maternal nutrition

\begin{tabular}{|l|l|l|}
\hline & Yes (\%) & No (\%) \\
\hline $\begin{array}{l}\text { Taken extra calories during } \\
\text { pregnancy and lactation }\end{array}$ & $174(87.00 \%)$ & $26(13.00 \%)$ \\
\hline $\begin{array}{l}\text { Taken supplements during } \\
\text { pregnancy and lactation }\end{array}$ & $162(81.00 \%)$ & $38(19.00 \%)$ \\
\hline
\end{tabular}

Table 4 shows that $87.00 \%$ mothers had taken extra calories and $81.00 \%$ had taken supplements during pregnancy and lactation. 


\section{International Journal of Science and Research (IJSR) \\ ISSN (Online): 2319-7064}

Index Copernicus Value (2013): 6.14 | Impact Factor (2014): 5.611

Table 5: Self assessment of mothers Response Number(\%)

\begin{tabular}{|l|l|}
\hline & Number (\%) \\
\hline Completely satisfied & $150(75.33 \%)$ \\
\hline Partly satisfied & $40(20.67 \%)$ \\
\hline Initially satisfied but not now & $4(2.00 \%)$ \\
\hline Initially had problems but now satisfied & $4(2.00 \%)$ \\
\hline Not satisfied & $2(1.00 \%)$ \\
\hline
\end{tabular}

Table 5 shows that $75.33 \%$ of mothers were completely satisfied with their infant feeding practice and only $1.00 \%$ being not satisfied.

\section{Conclusion}

In the present study, mothers had good knowledge about infant feeding practices. Inspite of good knowledge there are lacunae in the practices of mothers due to social and economic reasons. Level of education has positive impact on infant feeding practices. Counselling by doctors had a better impact on the attitude and practices of mothers. Knowledge, attitudes and practices associated with infant and young child feeding forms an essential first step for any 'need-felt' for an intervention programme designed to bring about positive behavioral change in infant health(7). The interaction during the study with the mothers was utilized as an opportunity to educate them regarding the importance and the recommended infant feeding practices. Breast-feeding has declined worldwide in recent years, as a result of urbanization, marketing of infant milk formulae and maternal employment outside the home (8). Studies in India have also shown a decline in breastfeeding trends, especially in urban areas $(9,10)$. It is important to provide appropriate health education and utilise every opportunity of contact with the mother to counsel them regarding the appropriate feeding practices.

\section{References}

[1] Pollitt E, et al. Nutrition in early life and the fulfilment of intellectual potential. The Journal of Nutrition.1995;125:1111S-1118S.

[2] Grantham-McGregor SM, Cumper G. Jamaican studies in nutrition and child development, and their implications for national development. The Proceedings of the Nutrition Society. 1992;51:71-79.

[3] Haas JD, et al. Early nutrition and later physical work capacity. Nutrition reviews. 1996;54(2,Pt2):S41-48.

[4] World Bank. Repositioning nutrition as central to development: a strategy for large scale action. Washington DC: The World Bank

[5] Jones G, et al. How many child deaths can we prevent this year? Lancet. 2003; 362:65-71.

[6] National guidelines on infant and young child feeding. Ministry of women and child development(Food and nutrition board)Government of India 2006 Available at:

[7] http://wcd.nic.in/nationalguidelines.pdf Accessed on May 26,2013

[8] RolfesSh.R ,DebruyneL.K., Whitney E.N,1998, Life Span Nutrition ,Conception Through Life, NewYork, Thomson, page 117-189.

[9] Emery J.L., Scholey S. and Taylor E.M.: Decline in Breastfeeding; Archives of Disease in Childhood, (1990), p. 369-372.
[10]Kapil U. and Verma D: Breast-feeding Practices in Scheduled.Caste Community in Haryana State; (1994) Indian Pediatric, 31, p. 1227- 1232.

[11] Chhabra P, Grover V.L., Aggrawal OP. and Dubey KK. (1998):Breast-feeding Pattern in Urban Resettlement Colony of Delhi, Indian J Pediatric, 65, p. 875-872.

\section{Author Profile}

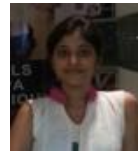

Dr. MaitryBhupendra Shah is Resident Doctor, Pediatrics Department, Civil Hospital, Ahmedabad, India

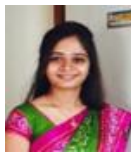

Dr. Purvi Patel is Assistant Professor (M.D.),Pediatrics Department, Civil Hospital, Ahmedabad, India

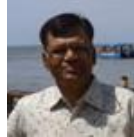

Dr. K. M. Mehariya is Professor and Head (M.D.) Pediatrics Department, Civil Hospital, Ahmedabad, India 